
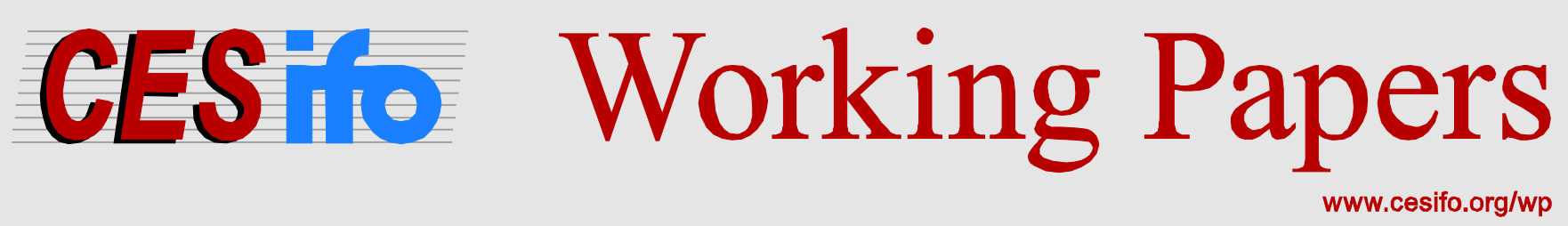

\title{
Controlling Product Risks when Consumers are Heterogeneously Overconfident: Producer Liability vs. Minimum Quality Standard Regulation
}

\author{
Andrzej Baniak \\ Peter Grajzl
}

CESIFO WORKING PAPER NO. 5003

CATEGORY 11: INDUSTRIAL ORGANISATION

OCTOBER 2014

An electronic version of the paper may be downloaded

- from the SSRN website:

- from the RePEc website:

- from the CESifo website:

www.SSRN.com

www.RePEc.org

www.CESifo-group.org/wp

\section{CESifo}




\title{
Controlling Product Risks when Consumers are Heterogeneously Overconfident: Producer Liability vs. Minimum Quality Standard Regulation
}

\begin{abstract}
Contributing to the literature on the consequences of behavioral biases for market outcomes and institutional design, we contrast producer liability and minimum quality standard regulation as alternative means of social control of product-related torts when consumers are heterogeneously overconfident about the risk of harm. We elucidate the role of factors shaping the relative desirability of strict liability vis-à-vis minimum quality standard regulation from a social welfare standpoint. We also clarify when and why joint use of strict liability and minimum quality standard regulation welfare dominates the exclusive use of either mode of social control of torts.
\end{abstract}

JEL-Code: K130, L510, D810, D030.

Keywords: product risk, overconfidence, consumer heterogeneity, tort law, minimum quality standard.

\author{
Andrzej Baniak \\ Department of Economics \\ Central European University \\ Nador u. 9 \\ Hungary-1051 Budapest \\ baniaka@ceu.hu
}

\author{
Peter Grajzl* \\ Department of Economics \\ The Williams School of Commerce, \\ Economics, and Politics \\ Washington and Lee University \\ USA - Lexington, VA 24450 \\ grajzlp@wlu.edu
}

*corresponding author

September 22, 2014

For helpful comments and suggestions, we thank Valentina Dimitrova-Grajzl, Botond Köszegi, Adam Szeidl, and participants at the annual meeting of the Canadian Law and Economics Association. Parts of this research were conducted during Peter Grajzl's research stay at the Center for Economic Studies (CES) in Munich. The authors express gratitude to the CES for their hospitality. 


\section{Introduction}

Litigation and government regulation are two key modes of social control of business (see, e.g., Shavell 1984b, Djankov et al. 2003, Shleifer 2005). The literature has devoted significant attention to comparing the functioning of liability law and government regulation as means of social control of torts in an environment where the tortfeasor and the victim are strangers without a contractual or other market connection. ${ }^{1}$ However, accidents also occur in settings where the tortfeasor and the harmed party are respectively a firm and its customer, bound by a market relationship. In such cases, the market price of the good adjusts to reflect the underlying risk and, hence, the implications of specific legal regimes are fundamentally different from those pertaining to the scenario where the tortfeasor and the victim are strangers (see, e.g., Miceli 1997: Ch. 2; Shavell 2004, Sec. II). Yet with the exception of a recent article by Miceli and Segerson (2013), we are aware of no other explicitly comparative account contrasting tort liability with government regulation applicable to situations where the tortfeasor and the harmed party are respectively a firm and its customer.

In this paper, we take steps toward filling this gap in the literature by comparing the performance of tort liability and regulation in the form of a minimum quality standard as means of controlling product risks to consumers. Following a lengthy series of previous contributions emphasizing the importance of behavioral biases in the context of perception of product-related risk, we assume that consumers are overconfident about, and thus systematically underestimate, the risk of product-caused harm (see, e.g., Spence 1977, Shavell 1980, Polinsky and Rogerson

\footnotetext{
${ }^{1}$ See e.g. Calabresi (1970), Wittman (1977), White and Wittman (1974), Shavell (1984a), Kolstad et al. (1990), Rose-Ackerman (1991), Trebilcock and Winter (1997), Burrows (1999), Glaeser and Shleifer (2003), Boyer and Porrini (2004, 2011), Schmitz (2000), Innes (2004), Hiriart et al. (2004, 2008), De Geest and Dari-Mattiacci (2007), Calcott and Hutton (2006), Rouillon (2008), Bhole and Wagner (2008), Lenntorp (2009), Dari-Mattiacci and Garoupa (2009), Schwartzstein and Shleifer (2013), Shavell (2012), and Desquilbet and Poret (2014). For analyses contrasting litigation and regulation outside of the torts context, see e.g. Glaeser et al. (2001), Garoupa and GomezPomar (2004), and Xu and Pistor (2005). For empirical studies of regulation versus litigation, see e.g. Helland and Klick (2006) and Bentata (2013, 2014).
} 
1983, Marino 1988; Sandroni and Squintani 2007, 2013). ${ }^{2,3}$ Unlike the existing literature that examines the consequences of consumer misperceptions of product risks, however, we examine a setting in which consumers are, very plausibly, heterogeneous with respect to the degree of their overconfidence. Such heterogeneity may be viewed as reflecting differences among consumers in predisposition toward risk, access to information, and even prior experience with related products.

When consumers are heterogeneously overconfident about the risk of product-related harm, we show that the competitive equilibrium under any of the considered modes of social control of business exhibits product differentiation. ${ }^{4}$ Products offered to consumers with greater overconfidence about the risk of harm are riskier, but less expensive, than the products offered to consumers that are less overconfident about risk. The precise level of implied risk for harm associated with a product offered to consumers of a particular type, and thus the social welfare implications, however, vary with the mode of social control of business.

The regime of laissez-faire, in which consumers themselves bear all product-related losses, leads to socially suboptimal outcomes because the levels of precaution chosen by competitive firms under laissez-faire are lower than the socially optimal precaution level for products offered to all consumer types. The introduction of strict producer liability incentivizes firms to increase their investment in precaution relative to the laissez-faire scenario. However,

\footnotetext{
${ }^{2}$ Consumers do not always underestimate the risk of harm. Evidence suggests that consumers tend to overestimate the risk of very low probability, high impact events, and underestimate the risk of comparatively high probability events (see Viscusi et al. 2005). We focus on the scenario when consumers underestimate (i.e. are overconfident about) risk as this is the primary scenario of interest in the literature on products liability (see, e.g., Spence 1977, Shavell 1980, Polinsky and Rogerson 1983, Marino 1988).

${ }^{3}$ De Bondt and Thaler (1995: 389) argue that "[p]erhaps the most robust finding in the psychology of judgment is that people are overconfident". Overconfidence has been studied in contexts other than perception of risk (see, e.g., Moore and Healy 2008, Hilton et al. 2011). For an overview of, and references on, theoretical, experimental, and empirical literature on overconfidence, see e.g. Rabin (1998: 31), Grubb (2009: 1773), DellaVigna (2009: 341-344), Sandroni and Squintani (2013:151-153), Hoffman and Post (2014: 23), Fellner-Röhling and Krügel (2014), and Brookins et al. (2014).

${ }^{4}$ Product differentiation under perfect competition is also a feature of the models developed by Ordover (1979) and Choi and Spier (2014).
} 
precaution levels under strict liability are nevertheless lower than first-best whenever the expected damages fall short of fully covering consumer losses in case of an accident for reasons such as firms' judgment proofness, abandoned lawsuits, or because monetary damages need not fully compensate consumers for non-pecuniary losses.

Unlike producer liability, which acts ex post, a minimum quality standard regulates firm behavior ex ante, before harm takes place. In our context, an optimal minimum quality standard specifies the level of precaution such that the gross consumer utility (i.e. utility if the product were perfectly safe) from the marginal product on the market exactly equals the expected harmrelated costs. Minimum quality standard regulation therefore removes from the market those products that under the laissez-faire regime yield a negative expected net social benefit. On the other hand, firms that obey the standard de facto behave as if the regime governing the industry were laissez-faire. With overconfident consumers, however, the products satisfying the specified minimum precaution standard feature levels of precaution that are too low relative to the firstbest level of precaution.

From a social welfare viewpoint, the benefits of minimum quality standard regulation therefore stem from the removal of the riskiest products - those aimed at consumers with greatest overconfidence bias - from the market. The costs arise because the remaining products, sold to consumers that are least overconfident about the risk of harm, are effectively governed by the rule of caveat emptor (i.e. laissez faire) and, hence, feature inadequately low levels of precaution. The benefits from strict producer liability arise from the mitigation of risk relative to laissez-faire. The costs arise because under strict liability, the firms in equilibrium continue to sell products to the consumers that are most overconfident about risk of harm. For these products, the expected net social benefit may be negative, which reduces overall social welfare. 
We ascertain that as long as the gross utility from the risky product is not excessively large, a plausible condition that we clarify below, the attractiveness of minimum quality standard regulation relative to strict producer liability decreases with the level of expected damages under strict producer liability and increases with the proportion of strongly overconfident consumers in the population. In contrast, the impact of the magnitude of harm, conditional on the accident having taken place, on the relative desirability of minimum quality standard regulation is in general ambiguous. The reason is that under both strict liability and minimum quality standard regulation the expected net social benefit from a product could either increase or decrease with the extent of incurred harm, an effect which in turn depends on the extent of consumer overconfidence about the risk of harm.

Finally, we examine the effectiveness of the joint use of minimum quality standard regulation and strict liability for addressing product-related risks. Several existing papers analyze the consequences of simultaneous reliance on regulation and tort law as a means of mitigating the risk of harm (see, e.g., Kolstad et al. 1990, Schmitz 2000, Bhole and Wagner 2008, Rouillon 2008, Lenntorp 2009, Miceli and Segerson 2013). Our contribution lies in analyzing the implications of combining strict liability with the enforcement of a minimum quality standard as a specific form of government regulation in a setting where the tortfeasor and the harmed party are a producer and a consumer bound through a market relationship.

From a social welfare standpoint, we find that, when the gross utility from the risky product is not excessively large, the joint use of minimum quality standard regulation and strict producer liability strictly dominates both the use of minimum quality standard regulation alone and reliance on strict producer liability on its own. The joint use of minimum quality standard regulation and strict liability strictly welfare dominates strict liability when under exclusive 
reliance on strict liability the market outcome admits trade of risky products that are sold to the most overconfident consumers and for which the expected net social benefit is negative. In this case, the introduction of the minimum quality standard to complement strict liability is beneficial as it is able to preclude the sale of these risky products.

At the same time, the joint use of minimum quality standard regulation and strict liability strictly welfare dominates the reliance on minimum quality standard regulation only, for two reasons. First, for those goods that already satisfy the minimum quality standard, strict liability increases firms' incentives to invest in precaution. Second, the presence of strict liability allows for promulgation and enforcement of a minimum quality standard that is less stringent than the optimal minimum quality standard in the absence of producer liability. The resulting increase in the sale of products that yield a positive expected net social benefit further contributes to the increase in social welfare relative to the scenario where firms are subject to minimum quality standard regulation only.

The rest of the paper proceeds as follows. In the following section, we discuss our contribution in the context of the most closely related literature. In Section 3, we develop the model's setup, characterize the first-best outcome, and present the equilibria under laissez faire, strict liability, and minimum quality standard regulation. In Section 4, we compare the regimes of strict liability and minimum quality standard regulation with laissez-faire, and with each other, from the social welfare standpoint. In Section 5, we examine the effectiveness of the joint use of strict liability and minimum quality standard regulation. Section 6 concludes.

\section{Related Literature}

To the best of our knowledge, the only other contribution that explicitly compares the use of tort liability and government regulation in the context of product-related risks is Miceli and Segerson 
(2013). There are several important differences between our setup and the model of Miceli and Segerson (2013). These differences lead to distinct trade-offs and welfare predictions about the merits of strict liability vis-à-vis government regulation, and their joint use, as means of social control of product risks.

First, Miceli and Segerson emphasize variation in gross valuation of the product and magnitude of harm as sources of heterogeneity among consumers. We, in contrast, aim to highlight the implications of consumer heterogeneity with respect to overconfidence about the risk of harm. We inter alia deduce comparative statics results on how changes in the underlying distribution of consumers with respect to their overconfidence affect the social desirability of producer liability relative to government regulation. ${ }^{5}$

Second, Miceli and Segerson view government regulation as a regime in which a benevolent planner sets a single standard that all firms adhere to. We, in contrast, examine the implications of a minimum quality standard. Under minimum quality standard regulation, firms who optimally choose precaution levels that are too low given the standard are prohibited from selling their products and are effectively removed from the market. On the other hand, firms that comply with the standard, a behavior which may include optimally selecting a level of precaution that exceeds that required by the standard, effectively operate under the caveat emptor rule. These features of minimum quality standard give rise to benefits and costs of government regulation that are notably different from those emphasized by Miceli and Segerson.

Third, Miceli and Segerson assume that under strict liability consumers are fully compensated for harm. In their framework, consumer perceptions of risk therefore do not matter

\footnotetext{
${ }^{5}$ Miceli and Segerson (2013) in Section 3 of their paper do touch upon the impact of consumer heterogeneity with respect to misperception of risk, but focus on a particular parametric example of such heterogeneity. Specifically, they assume that a proportion of consumers perceive risk correctly and that the remaining proportion of consumers is homogeneous with respect to their misperception of risk. Our setup is more general in that it allows for any pattern of heterogeneity with respect to consumers' overconfidence about risk from harm.
} 
under strict liability. We, in contrast, focus on the arguably more realistic scenario (see, e.g., Shavell 1984a, De Geest and Dari-Mattiaci 2007, Chen and Hua 2012) in which expected damages awarded by the courts in the case of an accident, for reasons described below, fall short of the total harm incurred by consumers. As a consequence, the extent of consumer overconfidence about the risk of harm directly shapes the equilibrium levels of precaution under strict liability. In particular, strict liability in our setting in general does not lead to first-best levels of precaution even though the price of a product reflects consumer-specific risk. Moreover, because the level of precaution chosen by a competitive firm depends on the extent to which the consumer is overconfident about the risk of product-related harm, equilibrium under strict producer liability exhibits product differentiation with respect to both the level of safety and the price of the product. This is not the case in the analysis of Miceli and Segerson (2013) where firms under strict liability choose a single profit-maximizing level of safety and the equilibrium price reflects the average risk across all consumers.

Our paper is also related to two broad strands of the behavioral economics literature. The first strand studies market outcomes when consumers exhibit a behavioral bias (see, e.g., DellaVigna and Malmeinder 2004, Gabaix and Laibson 2006, Spiegler 2006, Sandroni and Squintani 2007, 2013; Eliaz and Spiegler 2008, Grubb 2009, Spinnewijn 2013). We contribute to this literature by studying the interaction of competitive firms and consumers that are heterogeneously overconfident about product risk. The second strand of the literature explores the repercussions of behavioral biases for institutional design (see, e.g., Köszegi 2014, DelleVigna 2009: 364-365, Werden et al. 2011, Claussen et al. 2012, Cooper and Kovacic 2012). We add to this literature by analyzing the performance of producer liability and minimum quality 
standard regulation as means of social control of product-related torts when consumers are heterogeneously overconfident about product risks.

\section{The Model}

There is a large population of consumers. Each buys at most one unit of the product produced by competitive firms. Let $u>0$ be the benefit to the consumer from the consumption of the product if the product entailed no risk. The product, however, is risky. Let $\pi(x)$ be the objective probability that a product fails and harms the consumer, where $x \geq 0$ is the firm's level of precaution. We assume that $\pi^{\prime}<0, \pi^{\prime \prime}>0$, with $\pi^{\prime}(x) \rightarrow-\infty$ as $x \rightarrow 0$ and $\pi^{\prime}(x) \rightarrow 0$ as $x \rightarrow+\infty$. The level of precaution $x$ is assumed to equal the total cost of production of one unit of the good. The total (i.e. pecuniary and non-pecuniary) harm suffered by a consumer in case of an accident equals $h>0$.

The consumers suffer from a behavioral bias. The subjective probability of an accident as perceived by a consumer equals $\lambda \pi(x)$, where the parameter $\lambda \in(0,1]$ captures the extent of consumer overconfidence (see, e.g., Sandroni and Squintani 2007, 2013) or, equivalently, the extent of consumer underestimation of risk (see, e.g., Spence 1977, Polinsky and Rogerson 1983, Shavell 1980, Marino 1988; Miceli and Segerson 2013). The smaller the $\lambda$, the more overconfident the consumer is in that she discounts the extent of risk from harm more heavily. A consumer with $\lambda=1$ perceives the risk of harm correctly. Let $F(\lambda)$ be the cumulative distribution function of $\lambda$ and $f(\lambda)$ the associated probability density function. The consumers are thus identical in all but one respect: the extent of their overconfidence about the risk of productrelated harm. 


\subsection{First Best}

It is socially efficient for a consumer to buy a product if the net expected benefit from the product is at least as large as the cost of producing the product: $u-\pi(x) h \geq x$. Social welfare thus equals:

$$
W=\int_{0}^{1}[u-x-\pi(x) h] f(\lambda) d \lambda=u-x-\pi(x) h
$$

and is independent of $\lambda$. At first-best (FB), therefore, the marginal benefit of an additional unit of precaution equals the marginal cost:

$$
-\pi^{\prime}\left(x^{F B}(h)\right) h=1,
$$

where the first-best level of precaution $x^{F B}(h)$, defined by (2), is increasing in $h$. Throughout the paper, we assume that social welfare at the first-best precaution level is strictly positive: $W\left(x^{F B}(h)\right)=u-\chi^{F B}-\pi\left(x^{F B}\right) h>0$. This assumption ensures that it is socially desirable to sell a positive quantity of the product.

\subsection{The Notion of Equilibrium}

The product market is perfectly competitive, implying there is free entry and exit. Let $U(\lambda, x)$ denote the consumer's utility from the product excluding the price of the product but including expected harm-related costs and any compensation damages in the presence of producer liability. Let $C(x)$ be the firm's total cost that includes any compensation damage payments.

When $\lambda$ is a consumer's private information, firms compete by offering consumers contracts that specify the level of precaution $x$ and the price $p$ of a product. To characterize the equilibrium in such a competitive environment with asymmetric information, we invoke the 
notion of equilibrium proposed by Rothschild and Stiglitz (1976). ${ }^{6}$ The Rothschild-Stiglitz equilibrium is a set of contracts such that no firm incurs losses and given original contracts no additional contracts are profitable. In equilibrium, every firm thus earns zero profit on every consumer type and, at the same time, the utility of consumers of every type is maximized (see Salanie 2005: 58-59). Thus, for consumer of type $\lambda$, the Rothschild-Stiglitz equilibrium is characterized by a pair $\left(x^{*}, p^{*}\right)$ such that:

$$
\begin{gathered}
\frac{\partial U\left(x^{*}, \lambda\right)}{\partial x}=C^{\prime}\left(x^{*}\right) \\
p^{*}=C\left(x^{*}\right) .
\end{gathered}
$$

Importantly, the solution (3)-(4) characterizes a competitive equilibrium even if $\lambda$ is known to firms (rather than being the consumer's private information). When $\lambda$ is common knowledge, competition among firms will drive profits down to zero. The only competitive equilibrium with perfect information is therefore one in which the firms offer a family of contracts $(x, p)$ that solves the problem of maximizing $U(x, \lambda)-p$ subject to the constraint $p-C(x) \geq 0$ (see Salanie 2005: 59); that is, $\left(x^{*}, p^{*}\right)$ characterized by (3) and (4). Under the assumption of perfect competition, whether information about consumer types is common or private (and, hence, gives rise to adverse selection) is therefore "irrelevant" (ibid.).

\subsection{Equilibrium Under Laissez-Faire}

Under laissez-faire (LF), the rule of caveat emptor applies and consumers bear all the accidentrelated costs. For consumer of type $\lambda$, the utility excluding the price of the product equals $U(\lambda, x)=u-\lambda \pi(x) h$ and a firm's total cost equals $C(x)=x$. Applying expressions (3)-(4) to find the equilibrium gives:

\footnotetext{
${ }^{6}$ See e.g. Ordover (1979) and Choi and Spier (2014) for an analogous approach to defining a competitive equilibrium in an environment with heterogeneous consumers and competitive firms.
} 


$$
\begin{gathered}
-\pi^{\prime}\left(x^{L F}(\lambda, h)\right)=\frac{1}{\lambda h} \\
p^{L F}(\lambda, h)=x^{L F}(\lambda, h),
\end{gathered}
$$

where $x^{L F}(\lambda, h)$ and the equilibrium price $p^{L F}(\lambda, h)$ are increasing in both $\lambda$ and $h$ (see the Appendix). Observe that firm's precaution under laissez-faire falls short of first-best precaution whenever consumers are overconfident: $x^{L F}(\lambda, h)<x^{F B}(h)$ whenever $\lambda<1$. Since the expected net social benefit $u-x-\pi(x) h$ increases in the level of safety for $x<x^{F B}(h)$, social welfare under laissez-faire

$$
W^{L F}=\int_{0}^{1}\left[u-x^{L F}(\lambda, h)-\pi\left(x^{L F}(\lambda, h)\right) h\right] f(\lambda) d \lambda
$$

falls short of the first-best social welfare $W\left(x^{F B}(h)\right)$. Therefore, there exists scope for some form of social control of business to improve upon the laissez-faire outcome.

\subsection{Equilibrium Under Strict Liability}

Under strict liability (SL), producers are liable for consumer harm whenever it occurs. Let $d$ be the expected damages paid by a firm in case of an accident. That is, conditional on the harm having taken place, $d$ is the product of the probability that the firm is found liable in court and the damages awarded by the court. We assume that $d \leq h . d=h$ in the case of full compensation. However, a plaintiff may never file a lawsuit or abandon the case before the court issues a judgment (Shavell 1984b, De Geest and Dari-Mattiaci 2007). Firms may be judgment proof because of the possibility to file for bankruptcy or because of liability caps (Shavell 1984a, 1986). Furthermore, whenever non-pecuniary losses from accident-caused harm are important, court-awarded compensation, even if it exceeds the pecuniary losses from harm, need not cover total consumer losses (Nussim and Tabbach 2009: 173). Thus, very often $d<h$. 
Under strict liability, the utility excluding the price of the product for consumer of type $\lambda$ equals $U(\lambda, x)=u-\lambda \pi(x)(h-d)$ and the total cost to a firm equals $C(x)=x+\pi(x) d$. Applying expressions (3)-(4), the equilibrium is thus characterized by:

$$
\begin{gathered}
-\pi^{\prime}\left(x^{S L}(\lambda, h, d)\right)=\frac{1}{\lambda h+(1-\lambda) d} \\
p^{S L}(\lambda, h, d)=x^{S L}(\lambda, h, d)+\pi\left(x^{S L}(\lambda, h, d)\right) d .
\end{gathered}
$$

Observe that $x^{S L}(\lambda, h, d)>x^{L F}(\lambda, h)$ for $d>0 ; x^{S L}(\lambda, h, d)<X^{F B}(h)$ whenever $\lambda<1$ and $d<h$; and $X^{S L}(\lambda, h, d)=X^{F B}(h)$ if either $\lambda=1$ or $d=h$. For a given consumer type $\lambda$, strict liability induces greater precaution than laissez-faire, but the precaution level under strict liability falls short of first-best if consumers are overconfident and the expected damages do not fully cover consumer losses in case of an accident. Because $p^{S L}(\lambda, h, d)>x^{S L}(\lambda, h, d)>x^{L F}(\lambda, h)=p^{L F}(\lambda, h)$, it follows that the lower risk associated with a product under strict liability relative to laissez-faire comes at the cost of a higher price paid by the consumers. The equilibrium price $p^{S L}(\lambda, h, d)$ is increasing in all three of its arguments (see the Appendix). Social welfare under strict liability equals:

$$
W^{S L}=\int_{0}^{1}\left[u-x^{S L}(\lambda, h, d)-\pi\left(x^{S L}(\lambda, h, d)\right) h\right] f(\lambda) d \lambda .
$$

\subsection{Equilibrium Under Minimum Quality Standard Regulation}

Under minimum quality standard regulation, the regulator sets a minimum quality standard (MQS) implying a level of precaution $x^{M Q S}$ such that when a firm meets the standard ( $x \geq x^{M Q S}$ ), the firm is not liable in case of an accident. In contrast, firms that choose precaution levels that fail to satisfy the standard $\left(x<x^{M Q S}\right)$ are prohibited from selling the product. We assume that the 
minimum quality standard $x^{M Q S}$ is perfectly enforced. ${ }^{7}$ Minimum quality standard regulation is thus effectively the regime of laissez-faire subject to the constraint that all producing firms choose $x \geq x^{M Q S}$. Note that since $x^{L F}(\lambda, h)$ is increasing in $\lambda$, it may be that $x^{L F}(\lambda, h)<x^{M Q S}$ for small values of $\lambda$ and $x^{L F}(\lambda, h)>x^{M Q S}$ for values of $\lambda$ close to 1 . Thus, in equilibrium, some firms may optimally choose not to meet the minimum quality standard, and therefore not to sell the product, and at the same time a subset of firms may optimally choose to provide more safety than dictated by the standard.

We characterize the optimal minimum quality standard in Sections 4 and 5 below, where we contrast minimum quality standard regulation with other institutional regimes. For now, in order to characterize social welfare under a given minimum quality standard, suppose that the implemented minimum quality standard $x^{M Q S}$ is strictly positive. Accordingly, we can define $\lambda_{0}(h)$ as the unique solution to the expression $x^{L F}(\lambda, h)=x^{M Q S}$ for a given value of $x^{M Q S}>0 . \lambda_{0}(h)$ therefore denotes the maximum level of consumer overconfidence about the risk of harm such that the product offered by competitive firms to consumers of this type just satisfies the minimum quality standard $x^{M Q S}>0$. The social welfare then equals:

$$
W^{M Q S}=\int_{\lambda_{0}(h)}^{1}\left[u-x^{L F}(\lambda, h)-\pi\left(x^{L F}(\lambda, h)\right) h\right] f(\lambda) d \lambda .
$$

\section{Contrasting Regimes: Welfare Analysis}

We next contrast the social welfare under different regimes governing firm behavior. We first compare laissez-faire (LF) with strict liability (SL). ${ }^{8}$

Proposition 1 (LF vs. SL): $W^{S L}>W^{L F}$ for any $d \in(0, h]$.

\footnotetext{
${ }^{7}$ See Chen and Serfes (2012) for an analysis of minimum quality standard regulation when firms need not comply with the standard.

${ }^{8}$ See the Appendix for proofs of all results.
} 
The equilibrium level of precaution under laissez-faire falls short of the equilibrium level of precaution under strict liability for any positive expected damages under strict liability, for any consumer type $\lambda$. Because the expected net social benefit $u-x-\pi(x) h$ increases in the level of safety for $x<x^{F B}(h)$, the expected net social benefit from a product sold to consumer of type $\lambda$ under strict liability strictly exceeds the expected net social benefit from a product for that consumer type under laissez-faire: $u-x^{S L}(\lambda, h, d)-\pi\left(x^{S L}(\lambda, h, d)\right) h>u-x^{L F}(\lambda, h)-\pi\left(x^{L F}(\lambda, h)\right) h$ (see Figure 1 for an illustrative example). Social welfare under strict liability thus exceeds social welfare under laissez-faire.

We next characterize the optimal minimum quality standard and contrast minimum quality standard regulation (MQS) with laissez-faire (LF).

Proposition 2 (LF vs. MQS): Suppose that $u-\chi^{L F}(\lambda, h)-\pi\left(x^{L F}(\lambda, h)\right) h<0$ as $\lambda \rightarrow 0$. Then, the optimal minimum quality standard $x^{M Q S}>0$ is the unique solution to the expression $u-x-\pi(x) h=0$, and $W^{M Q S}>W^{L F}$. In contrast, if $u-x^{L F}(\lambda, h)-\pi\left(x^{L F}(\lambda, h)\right) h \geq 0$ for all $\lambda \in(0,1]$, the optimal minimum quality standard $x^{M Q S}=0$, and $W^{M Q S}=W^{L F}$.

To understand the characteristics of the optimal minimum quality standard when the default regime is laissez-faire, suppose that the gross consumer utility from the product $(u)$ is not excessively large so that the expected net social benefit from a product under laissez-faire, $u-\chi^{L F}(\lambda, h)-\pi\left(x^{L F}(\lambda, h)\right) h$, is negative for some products. Since $u-\chi^{L F}(\lambda, h)-\pi\left(x^{L F}(\lambda, h)\right) h$ is increasing in $x^{L F}(\lambda, h)$ and $x^{L F}(\lambda, h)$ is in turn increasing in $\lambda$, the expected net social benefit is negative for those products that are under laissez-faire offered to the group of the most overconfident consumers (i.e. consumers with small values of $\lambda$ ). Then, the optimal minimum quality standard $x^{M Q S}>0$ is the level of precaution such that the gross consumer utility from the marginal product on the market $(u)$ exactly equals expected harm-related cost $(x+\pi(x) h)$. In this case, social welfare under minimum quality standard regulation strictly exceeds the social 
welfare under laissez-faire. In contrast, if the expected net social benefit from a product under laissez-faire is always positive (as would be the case when $u$ is very large), the introduction of the minimum quality standard is superfluous; the optimal minimum quality standard is $x^{M Q S}=0 .{ }^{9}$

Propositions 1 and 2 suggest that both strict liability and minimum quality standard regulation may improve social welfare relative to the laissez-faire scenario. Yet which mode of social control of product-related torts - minimum quality standard regulation (MQS) or strict liability (SL) - should be used when? To address this question, we focus on the scenario when the introduction of the appropriate minimum quality standard increases social welfare relative to the laissez-faire case (see Proposition 2). ${ }^{10}$

Proposition 3 (MQS vs. SL): Suppose that $u-x^{L F}(\lambda, h)-\pi\left(x^{L F}(\lambda, h)\right) h<0$ as $\lambda \rightarrow 0$ and $0<d<h$. Define $\Delta^{M Q S, S L} \equiv W^{M Q S}-W^{S L}$.

1. If $u-x^{S L}(\lambda, h, d)-\pi\left(x^{S L}(\lambda, h, d)\right) h>0$ for all $\lambda \in(0,1]$, then $\Delta^{M Q S, S L}<0$.

2. If $u-x^{S L}(\lambda, h, d)-\pi\left(x^{S L}(\lambda, h, d)\right) h<0$ as $\lambda \rightarrow 0$, then:

(i) $\Delta^{M Q S, S L}$ is decreasing in $d$ and in $u$ so that for $d$ sufficiently close to $h$ or for $u$ sufficiently large, $\Delta^{\mathrm{MQS}, S L_{<}}<0$.

(ii) Let $F_{A}(\lambda)$ and $F_{B}(\lambda)$ be cumulative distribution functions defined on $\lambda \in(0,1]$ and $f_{A}(\lambda)$ and $f_{B}(\lambda)$ the associated probability density functions with the following properties:

(a) $f_{A}(\lambda) \leq f_{B}(\lambda)$ for all $\lambda \in\left(0, \lambda_{1}\right)$ and there exists a set $O_{1} \subseteq\left(0, \lambda_{1}\right)$ with $\mu\left(O_{1}\right)>0$ such that $f_{A}(\lambda)<f_{B}(\lambda)$ for all $\lambda \in O_{1}$,

(b) $f_{A}(\lambda) \geq f_{B}(\lambda)$ for all $\lambda \in\left(\lambda_{1}, 1\right]$ and there exists a set $O_{2} \subseteq\left(\lambda_{1}, 1\right]$ with $\mu\left(O_{2}\right)>0$ such that $f_{A}(\lambda)>f_{B}(\lambda)$ for all $\lambda \in O_{2}$,

where $\lambda_{1}=\lambda_{1}(h, d)$ is defined by the expression $u-x^{S L}(\lambda, h, d)-\pi\left(x^{S L}(\lambda, h, d)\right) h=0$ and $\mu(\cdot)$ is a Lebesgue measure. Then, $F_{A}(\lambda)$ first order stochastically dominates $F_{B}(\lambda)$ and $\Delta^{M Q S, S L}$ under $F_{B}(\lambda)$ is greater than $\Delta^{M Q S, S L}$ under $F_{A}(\lambda)$.

(iii) The effect of $h$ on $\Delta^{M Q S, S L}$ is ambiguous.

\footnotetext{
${ }^{9}$ One may argue that when taking into account the fixed costs of setting up and enforcing the regulatory regime, which we assume away in our analysis, laissez-faire would in this case strictly dominate minimum quality standard regulation from the social welfare viewpoint.

${ }^{10}$ If the introduction of a minimum quality standard cannot increase social welfare above the level attained under laissez-faire (this occurs when $u-\chi^{L F}(\lambda, h)-\pi\left(x^{L F}(\lambda, h)\right) h \geq 0$ for all $\lambda \in(0,1]$; see Proposition 2), then, since $u-X^{S L}(\lambda, h, d)-\pi\left(X^{S L}(\lambda, h, d)\right)>u-\chi^{L F}(\lambda, h)-\pi\left(X^{L F}(\lambda, h)\right) h$ for all $\lambda \in(0,1]$, strict liability strictly welfare dominates minimum quality standard regulation.
} 
Part 1 of Proposition 3 states that when under strict liability the expected net social benefit is positive for all products (a condition that is met when, for example, $u$ is sufficiently large), strict liability always strictly welfare dominates minimum quality standard regulation. Intuitively, because the equilibrium level of safety is higher under strict liability than under laissez-faire for all product types, it follows that the expected net social benefit is also higher under strict liability than under laissez-faire for all product types. When, in addition, the expected net social benefit under strict liability is strictly positive for all products, minimum quality standard regulation alone cannot increase social welfare beyond the level attained under strict liability.

In contrast, when the gross consumer utility from the product $(u)$ given the expected costs from product-related harm is sufficiently small, strict liability admits the sale of products offered to the consumers that strongly underestimate the risk of harm; for these products the expected net social benefit is negative. In this case, minimum quality standard regulation, by precluding the sale of the most risky products, may potentially increase social welfare beyond the level attained under strict liability even though the level of safety for the products that remain on the market under minimum quality standard regulation falls short of the level of safety that would have obtained had the regime in place been strict producer liability. Part 2 of Proposition 3 suggests that in this case the comparison of minimum quality standard regulation and strict liability from the social welfare viewpoint depends on the gross consumer utility from the product $(u)$, the level of expected damages awarded by the courts $(d)$, the underlying distribution of consumers according to their overconfidence about risk of harm, and the extent of harm if an accident takes place $(h)$. 
Whenever the expected damages $d$ are sufficiently close to the level of consumer harm $h$, the firms' choice of precaution under strict liability approaches that under first best. Social welfare under strict liability thus exceeds social welfare under minimum quality standard regulation. Similarly, if the consumer benefit from the consumption of the product in the absence of risk $(u)$ is sufficiently large, so that the introduction of a minimum quality standard regulation is superfluous relative to laissez-faire (see Proposition 1), social welfare is greater under strict liability than under minimum quality standard regulation (Proposition 3, part 2(i)).

The relative attractiveness of minimum quality standard regulation vis-à-vis strict liability increases with the proportion of consumers that are most overconfident about the risk of harm (Proposition 3, part 2(ii)). Intuitively, as the share of highly overconfident consumers increases, so does the volume of products, sold under strict liability, that yield a negative expected net social benefit. In this scenario, the benefits of the removal of all relatively risky products from the market (see Figure 1) outweigh the costs: the loss of social surplus which arises because the enforcement of the minimum quality standard eliminates from the market even those products for which the expected net social benefit would have been (marginally) positive under the strict liability regime. In interpreting part 2(ii) of Proposition 3, note that the condition that distribution A first-order stochastically dominates distribution B is necessary but not sufficient for a change in the distribution of the degree of overconfidence in the consumer population to alter the relative attractiveness of minimum quality standard regulation vis-à-vis strict liability. What is crucial is that the shift in the distribution function of $\lambda$ be such that there is an increase in the proportion of consumers with greatest level of overconfidence, i.e. with $\lambda<\lambda_{1}$, where $\lambda_{1}$ is illustrated in Figure 1. Figure 2 illustrates part 2(ii) of Proposition 3 for the simple example where $F_{A}(\lambda)$ is uniform distribution. 
Finally, the impact of the extent of harm conditional on the occurrence of an accident $(h)$ on the relative desirability of strict liability versus minimum quality standard regulation is ambiguous (Proposition 3, part 2(iii)), for the following reason. On the one hand, an increase in $h$ changes the cutoff level of consumer overconfidence $\lambda_{0}(h)$ associated with the marginal product permitted on the market under the minimum quality standard $x^{M Q S}$. However, the induced effect of a change in $h$ through $\lambda_{0}(h)$ on social welfare under minimum quality standard regulation vanishes because the expected net social benefit from the marginal product permitted on the market under the minimum quality standard $x^{M Q S}$ equals zero. On the other hand, an increase in $h$ incentivizes firms serving overconfident consumers to increase precaution under both strict producer liability and minimum quality standard regulation. This, in turn, decreases the likelihood of accident under both governance regimes, rendering ambiguous in sign, first, the total effect of $h$ on the expected net social benefit from a product under either governance regime and, second, as a consequence, the total effect of $h$ on the relative desirability of strict liability versus minimum quality standard regulation from the social welfare standpoint. ${ }^{11}$

\section{Joint Use of Strict Liability and Minimum Quality Standard Regulation}

In the previous sections, we demonstrated that both strict liability and minimum quality standard regulation for different reasons fall short of attaining the first-best level of social welfare. Moreover, we showed that depending on the parameter values, social welfare under minimum quality standard regulation may be greater or smaller than social welfare under strict liability. Consider now the scenario when the introduction of the optimal minimum quality standard increases social welfare above the level attained under laissez-faire (see Propositions 2 and 3); that is, when gross consumer utility from the product $(u)$ is not excessively large. Is it ever

\footnotetext{
${ }^{11}$ See the Appendix for a detailed exposition of all channels through which $h$ affects $\Delta^{M Q S, S L}$.
} 
beneficial to combine strict liability with minimum quality regulation and, if so, under what conditions does the joint use of minimum quality standard regulation and strict liability (MQS+SL) welfare dominate strict liability (SL) only and minimum quality standard regulation (MQS) only? The following result provides the answer.

Proposition 4 (MQS+SL vs. SL; MQS+SL vs. MQS): Suppose that $u-\chi^{L F}(\lambda, h)-\pi\left(X^{L F}(\lambda, h)\right) h<0$ as $\lambda \rightarrow 0$ and $0<d<h$.

1. If $u-x^{S L}(\lambda, h, d)-\pi\left(x^{S L}(\lambda, h, d)\right) h>0$ for all $\lambda \in(0,1]$, then:

(i) the optimal minimum quality standard in the presence of strict liability $x^{M Q S \mid S L}=0$,

$$
W^{M Q S+S L}=\int_{0}^{1}\left[u-x^{S L}(\lambda, h, d)-\pi\left(x^{S L}(\lambda, h, d)\right) h\right] f(\lambda) d \lambda,
$$

(iii) $\quad W^{M Q S+S L}=W^{S L}>W^{M Q S}$.

2. If $u-X^{S L}(\lambda, h, d)-\pi\left(x^{S L}(\lambda, h, d)\right) h<0$ as $\lambda \rightarrow 0$, then:

(i) the optimal minimum quality standard in the presence of strict liability $x^{M Q S \mid S L}=x^{S L}\left(\lambda_{1}, h, d\right)>0$, where $\lambda_{1}=\lambda_{1}(h, d)$ is defined in Proposition 3,

$$
\begin{aligned}
& W^{M Q S+S L}=\int_{\lambda_{1}(h, d)}^{1}\left[u-x^{S L}(\lambda, h, d)-\pi\left(x^{S L}(\lambda, h, d)\right) h\right] f(\lambda) d \lambda, \\
& W^{M Q S+S L}>W^{S L} \text { and } W^{M Q S+S L}>W^{M Q S} .
\end{aligned}
$$

Part 1 of Proposition 4 clarifies that if under strict liability the expected net social benefit is positive for all products, as would be the case when the gross consumer utility from the product $(u)$ is sufficiently large, the introduction of minimum quality standard regulation on top of strict liability does not yield any social welfare benefits. ${ }^{12}$ Because strict liability strictly welfare dominates minimum quality regulation under these circumstances (see Proposition 3, part 1), joint use of strict liability and minimum quality regulation strictly welfare dominates the exclusive reliance on minimum quality standard regulation. In contrast, when under strict liability the expected net social benefit is negative for some products (those offered to consumers that are most overconfident about the risk of harm), as would be the case when the gross

\footnotetext{
${ }^{12}$ Again, given inevitable fixed costs of regime set-up and operation that we assume away in our analysis, strict liability would in fact be strictly preferred to the joint use of strict liability and regulation.
} 
consumer utility from the product $(u)$ is not excessively large, the joint use of minimum quality standard regulation and strict liability from the social welfare viewpoint strictly dominates both minimum quality standard regulation only and strict liability only (Proposition 4, part 2).

Proposition 4, part 2, is best illustrated with Figure 1. Intuitively, the joint use of minimum quality standard regulation and strict liability strictly welfare dominates strict liability only because minimum quality standard regulation eliminates from the market those most risky products for which the expected net social benefit is negative: the set of products offered to consumer of type $\lambda$ such that $\lambda \in\left(0, \lambda_{1}\right)$. Similarly, the joint use of minimum quality standard regulation and strict liability welfare dominates minimum quality standard regulation only. First, the introduction of strict liability increases firms' incentives to invest in precaution for those products that already satisfy the minimum quality standard: product types $\lambda \in\left(\lambda_{0}, 1\right]$. Second, the presence of strict liability allows for promulgation and enforcement of a minimum quality standard that is laxer than the optimal minimum quality standard in the absence of producer liability: $x^{M Q S \mid S L}=x^{S L}\left(\lambda_{1}, h, d\right)<x^{M Q S}$. The resulting increase in the sale of products with a positive expected net social benefit further contributes to the increase in social welfare relative to the scenario where firms are subject to minimum quality standard regulation only.

\section{Conclusion}

While the literature has extensively examined the effectiveness of tort law and government regulation when the injurers and the victims are strangers not bound by a market relationship, little has been said about the comparative effectiveness of tort law and regulation in the likewise commonplace scenario when the injurers and the victims are respectively firms and their customers. Contributing to the literature that studies market outcomes in the presence of behaviorally biased consumers and emphasizes the salience of behavioral biases for institutional 
design, we contrast the performance of strict producer liability and minimum quality standard regulation, as well as their joint use, as alternative means of social control of business in a setting where competitive firms serve consumers who are heterogeneously overconfident about the risk of product-related harm.

Acting ex post, strict liability provides an incentive for the firms to increase their investment in precaution relative to the levels of precaution attained under laissez-faire, when the rule of caveat emptor applies. However, under strict liability a combination of institutional restrictions (such as judgment-proofness, abandoned lawsuits, and importance of non-pecuniary costs) on the magnitude of expected damage payments awarded by courts and consumer overconfidence about the risk from harm prevents the implementation of the first-best level of precaution and leads to the sale of products with socially excessive levels of expected harm. In contrast to strict producer liability, minimum quality standard regulation acts ex ante and eliminates from the market all products with inadequately low levels of precaution that would have otherwise been sold under laissez-faire. For the products remaining on the market, however, caveat emptor applies again and, thus, firms underinvest in precaution to a greater extent than they would have under strict liability.

Whenever the gross utility (i.e. utility in the absence of product risk) that consumers derive from the product is not too large relative to expected harm-related costs, the strict liability equilibrium involves trade of products, offered to consumers that are most overconfident about the risk of harm, for which the expected net social benefit is negative. In this case, the relative attractiveness of minimum quality standard regulation versus strict liability decreases with the gross consumer utility from the product, increases with the discrepancy between total harm and the expected damage payments awarded by the courts, and decreases as the proportion of 
consumers that are most overconfident about the risk of harm decreases. In contrast, the effect of total harm, conditional on accident taking place, is in general ambiguous. Finally, joint use of strict liability and minimum quality standard regulation strictly welfare dominates both the use of strict liability alone and the exclusive reliance on minimum quality standard regulation. 


\section{References}

Bentata, Pierre. 2013. "Environmental Regulation and Civil Liability Under Causal Uncertainty: An Empirical Study of the French Legal System." Review of Law and Economics, 9:2, 239263.

Bentata, Pierre. 2014. "Liability as a Complement to Environmental Regulation: An Empirical Study of the French Legal System." Environmental Economics and Policy Studies, forthcoming.

Bhole, Bharat and Jeffrey Wagner. 2008. "The Joint Use of Regulation and Strict Liability with Multidimensional Care and Uncertain Conviction." International Review of Law and Economics, 28:2, 123-132.

Boyer, Marcel and Donatella Porrini. 2004. "Modeling the Choice between Regulation and Liability in Terms of Social Welfare." Canadian Journal of Economics, 37:3, 590-612.

Boyer, Marcel and Donatella Porrini. 2011. "The Impact of Court Errors on Liability Sharing and Safety Regulation for Environmental/Industrial Accidents." International Review of Law and Economics, 31:1, 21-29.

Brookins, Philip, Adriana Lucas, and Dmitry Ryvkin. 2014. "Reducing Within-Group Overconfidence Through Group Identity and Between-Group Confidence Judgments." Journal of Economic Psychology, 44, 1-12.

Burrows, Paul. 1999. "Combining Regulation and Legal Liability for the Control of External Costs." International Review of Law and Economics, 19:2, 227-244.

Calabresi, Guido. 1970. The Costs of Accidents: A Legal and Economic Analysis. New Haven: Yale University Press.

Calcott, Paul and Stephen Hutton. 2006. "The Choice of a Liability Regime When There is a Regulatory Gatekeeper." Journal of Environmental Economics and Management, 51:2, 133258.

Chen, Min and Konstantinos Serfes. 2012. "Minimum Quality Standard Regulation Under Imperfect Quality Observability." Journal of Regulatory Economics, 41:2, 269-291.

Chen, Yongmin and Xinyu Hua. 2012. "Ex Ante Investment, Ex Post Remedies, and Product Liability." International Economic Review, 53:3, 845-866.

Choi, Albert H. and Kathryn E. Spier. 2014. "Should Consumers be Permitted to Waive Products Liability? Product Safety, Private Contracts, and Adverse Selection." Forthcoming in Journal of Law, Economics, and Organization. doi: 10.1093/jleo/ewt019.

Claussen, Carl Andreas, Egil Matsen, Oistein Roisland, and Ragnar Torvik. 2012. "Overconfidence, Monetary Policy Committees and Chairman Dominance." Journal of Economic Behavior and Organization, 81, 699-711.

Cooper, James and William Kovacic. 2012. "Behavioral Economics: Implications for Regulatory Behavior." Journal of Regulatory Economics, 41:1, 41-58.

Dari-Mattiacci, Giuseppe and Nuno Garoupa. 2009. "Least-Cost Avoidance: The Tragedy of Common Safety." Journal of Law, Economics, and Organization, 25:1, 235-261.

De Geest, Gerrit and Giuseppe Dari-Mattiacci. 2007. "Soft Regulators, Tough Judges." Supreme Court Economic Review, 15, 119-140. 
DellaVigna, Stefano. 2009. "Psychology and Economics: Evidence from the Field." Journal of Economic Literature, 47:2, 315-372.

DellaVigna, Stefano and Ulrike Malmendier. 2004. "Contract Design and Self-Control: Theory and Evidence." Quarterly Journal of Economics, 119:2, 353-402.

De Bondt, Werner F.M. and Richard H. Thaler. 1995. "Financial Decision-Making in Markets and Firms: A Behavioral Perspective." In: Jarrow, Robert, Vojislav Maksimovic and William T. Ziemba (eds.), Handbooks in Operations Research and Management, Vol. 9. Elsevier Science, Amsterdam, 385-410.

Desquilbet, Marion and Sylvaine Poret. 2014. "How Do GM/Non GM Coexistence Regulations Affect Markets and Welfare?" European Journal of Law and Economics, 37:1, 51-82.

Djankov, Simeon, Edward Glaeser, Rafael La Porta, Florencio Lopez-de-Silanes, and Andrei Shleifer. 2003. "The New Comparative Economics." Journal of Comparative Economics, 31, 595-619.

Eliaz, Kfir and Ran Spiegler. 2008. "Consumer Optimism and Price Discrimination." Theoretical Economics, 3:4, 459-497.

Fellner-Röhling, Gerlinde and Sebastian Krügel. 2014. "Judgmental Overconfidence and Trading Activity." Journal of Economic Behavior and Organization, forthcoming.

Gabaix, Xavier and David Laibson. 2006. "Shrouded Attributes, Consumer Myopia, and Information Suppression in Competitive Markets." Quarterly Journal of Economics, 121:2, 505-540.

Garoupa, Nuno and Fernando Gomez-Pomar. 2004. "Punish Once or Punish Twice: A Theory of the Use of Criminal Sanctions in Addition to Regulatory Penalties." American Law and Economics Review, 6:2, 410-433.

Glaeser, Edward, and Andrei Shleifer. 2003. "The Rise of the Regulatory State." Journal of Economic Literature, 41:2, 401-425.

Glaeser, Edward, Simon Johnson, and Andrei Shleifer. 2001. "Coase vs. the Coasians: The Regulation and Development of Securities Markets in the Czech Republic and Poland." Quarterly Journal of Economics, 116:3, 853-899.

Grubb, Michael D. 2009. "Selling to Overconfident Consumers." American Economic Review, 99:5, 1770-1807.

Helland, Eric and Jonathan Klick. 2006. "The Tradeoffs between Regulation and Litigation: Evidence from Insurance Class Actions." Journal of Tort Law, 1:3, Article 2.

Hilton, Denis, Isabelle Regner, Laure Cabantous, Laetitia Charalambides, and Stephane Vautier. 2011. "Do Positive Illusions Predict Overconfidence in Judgment? A Test Using Interval Production and Probability Evaluation Measures of Miscalibration." Journal of Behavioral Decision Making, 24, 117-139.

Hiriart, Yolande, David Martimort, and Jerome Pouyet. 2004. "On the Optimal Use of Ex Ante Regulation and Ex Post Liability." Economics Letters, 84:2, 231-235.

Hiriart, Yolande, David Martimort, and Jerome Pouyet. 2008. "The Regulator and the Judge: The Optimal Mix in the Control of Environmental Risk." Revue d'Economie Politique, 0:6, 941967. 
Hoffmann, Arvid O.I. and Thomas Post. 2014. "Self-Attribution Bias in Consumer Financial Decision-Making: How Investment Returns Affect Individuals' Belief in Skill." Journal of Experimental and Behavioral Economics, 52, 23-28.

Innes, Robert. 2004. "Enforcement Costs, Optimal Sanctions, and the Choice Between Ex-Post Liability and Ex-Ante Regulation." International Review of Law and Economics, 24:1, 29-48.

Kolstad, Charles D., Thomas S. Ulen, and Gary V. Johnson. 1990. "Ex Post Liability for Harm vs. Ex Ante Safety Regulation: Substitutes or Complements?" American Economic Review, 80:4, 888-901.

Köszegi, Botond. 2014. "Behavioral Contract Theory." Journal of Economic Literature, forthcoming.

Lenntorp, Erik. 2009. "On the Joint Use of Licensing and Liability." International Review of Law and Economics, 29:3, 244-251.

Marino, Anthony M. 1988a. "Monopoly, Liability and Regulation." Southern Economic Journal, 54:4, 913-927.

Marino, Anthony M. 1988b. "Products Liability and Scale Effects in a Long-Run Competitive Equilibrium." International Review of Law and Economics, 8, 97-107.

Miceli, Thomas J. and Kathleen Segerson. 2013. "Liability versus Regulation for Dangerous Products When Consumers Vary in Their Susceptibility to Harm and May Misperceive Risk." Review of Law and Economics, 9:3, 341-355.

Moore, Don A. and Paul J. Healy. 2008. "The Trouble with Overconfidence." Psychological Review, 115, 502-517.

Nussim, Jacob and Avraham D. Tabbach. 2009. "A Revised Model of Unilateral Accidents." International Review of Law and Economics, 29:2, 169-177.

Ordover, Janusz A. 1979. "Products Liability in Markets with Heterogeneous Consumers." Journal of Legal Studies, 8:3, 505-525.

Polinsky, A. Mitchell and William P. Rogerson. 1983. "Products Liability, Consumer Misperceptions, and Market Power." Bell Journal of Economics, 14:2, 581-589.

Rose-Ackerman, Susan. 1991. "Regulation and the Law of Torts." American Economic Review Papers and Proceedings, 81:2, 54-58.

Rabin, Matthew. 1998. "Psychology and Economics." Journal of Economic Literature, 36:1, 1146.

Rothschild, Michael and Joseph Stiglitz. 1976. "Equilibrium in Competitive Insurance Markets: An Essay on the Economics of Imperfect Information." Quarterly Journal of Economics, 90:4, 629-549.

Rouillon, Sebastien. 2008. "Safety Regulation vs. Liability With Heterogeneous Probabilities of Suit." International Review of Law and Economics, 28:2, 133-139.

Salanie, Bernard. 2005. The Economics of Contracts, A Primer, Second Edition, The MIT Press.

Sandroni, Alvaro and Francesco Squintani. 2007. "Overconfidence, Insurance, and Paternalism." American Economic Review, 97:5, 1994-2004.

Sandroni, Alvaro and Francesco Squintani. 2013. "Overconfidence and Asymmetric Information: The Case of Insurance." Journal of Economic Behavior and Organization, 93, 149-165. 
Schmitz, Patrick W. 2000. "On the Joint Use of Liability and Safety Regulation." International Review of Law and Economics, 20:3, 371-382.

Schwartzstein, Joshua and Andrei Shleifer. 2013. "An Activity-Generating Theory of Regulation." Journal of Law and Economics, 56, 1-38.

Shavell, Steven. 1980. "Strict Liability versus Negligence." Journal of Legal Studies, 9:1, 1-25.

Shavell, Steven. 1984a. "A Model of the Optimal Use of Liability and Safety Regulation." RAND Journal of Economics, 15:2, 271-281.

Shavell, Steven. 1984b. "Liability for Harm versus Regulation of Safety." Journal of Legal Studies, 13:2, 357-374.

Shavell, Steven. 1986. "The Judgment Proof Problem." International Review of Law and Economics, 6:1, 45-68.

Shavell, Steven. 2004. Foundations of Economic Analysis of Law. Belknap Press/Harvard University Press.

Shavell, Steven. 2012. "A Fundamental Enforcement Cost Advantage of the Negligence Rule over Regulation." NBER Working Paper No. 18418.

Shleifer, Andrei. 2005. "Understanding Regulation." European Financial Management, 11:4, 439-451.

Spence, Michael. 1977. "Consumer Misperceptions, Product Failure, and Producer Liability." Review of Economic Studies, 44:3, 561-572.

Spiegler, Ran. 2006. "Competition over Agents with Boundedly Rational Expectations." Theoretical Economics, 1:2, 207-231.

Spinnewijn, Johannes. 2013. "Insurance and Perceptions: How to Screen Optimists and Pessimists." Economic Journal, 123, 606-633.

Trebilcock, Michael and Ralph A. Winter. 1997. "The Economics of Nuclear Accident Law." International Review of Law and Economics, 17:2, 215-243.

Viscusi, W. Kip, John M. Vernon, and Joseph E. Harrington, Jr. 2005. Economics of Regulation and Antitrust, Fourth Edition. Cambridge, Massachusetts: The MIT Press.

Werden, Gregory J., Luke M. Froeb, and Mikhael Shor. 2011. "Behavioral Antitrust and Merger Control." Journal of Institutional and Theoretical Economics, 167:1, 126-142.

White, Michelle J. and Donald Wittman. 1983. "A Comparison of Taxes, Regulation, and Liability Rules under Imperfect Information." Journal of Legal Studies, 12:2, 413-425.

Wittman, Donald. 1977. "Prior Regulation versus Post Liability: The Choice between Input and Output Monitoring." Journal of Legal Studies, 6:1, 193-211.

$\mathrm{Xu}$, Chenggang and Katharina Pistor. 2005. "Enforcement Failure under Incomplete Law: Theory and Evidence from Financial Market Regulations." Working paper. 


\section{Figures}

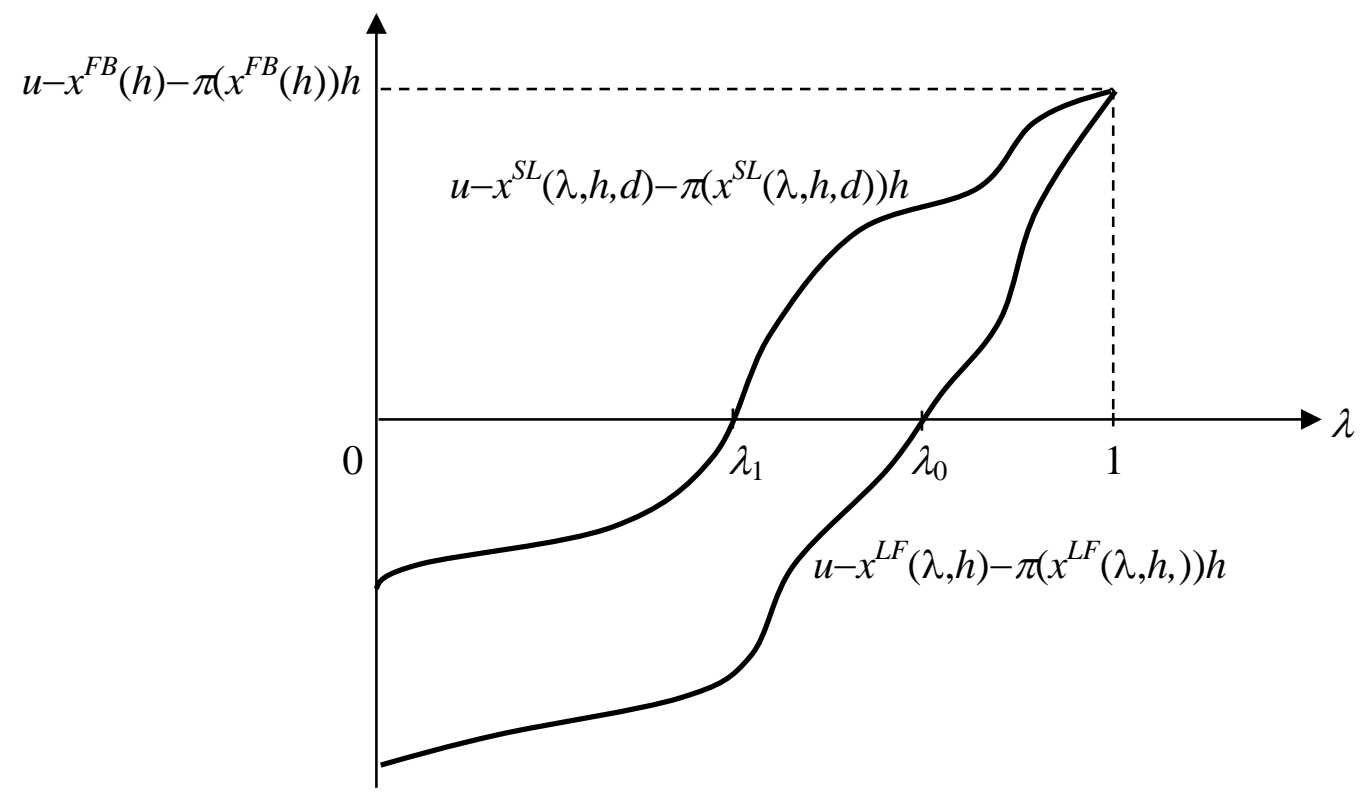

Figure 1: Expected net social benefit from a product as a function of the degree of consumer overconfidence about the risk of product-related harm.

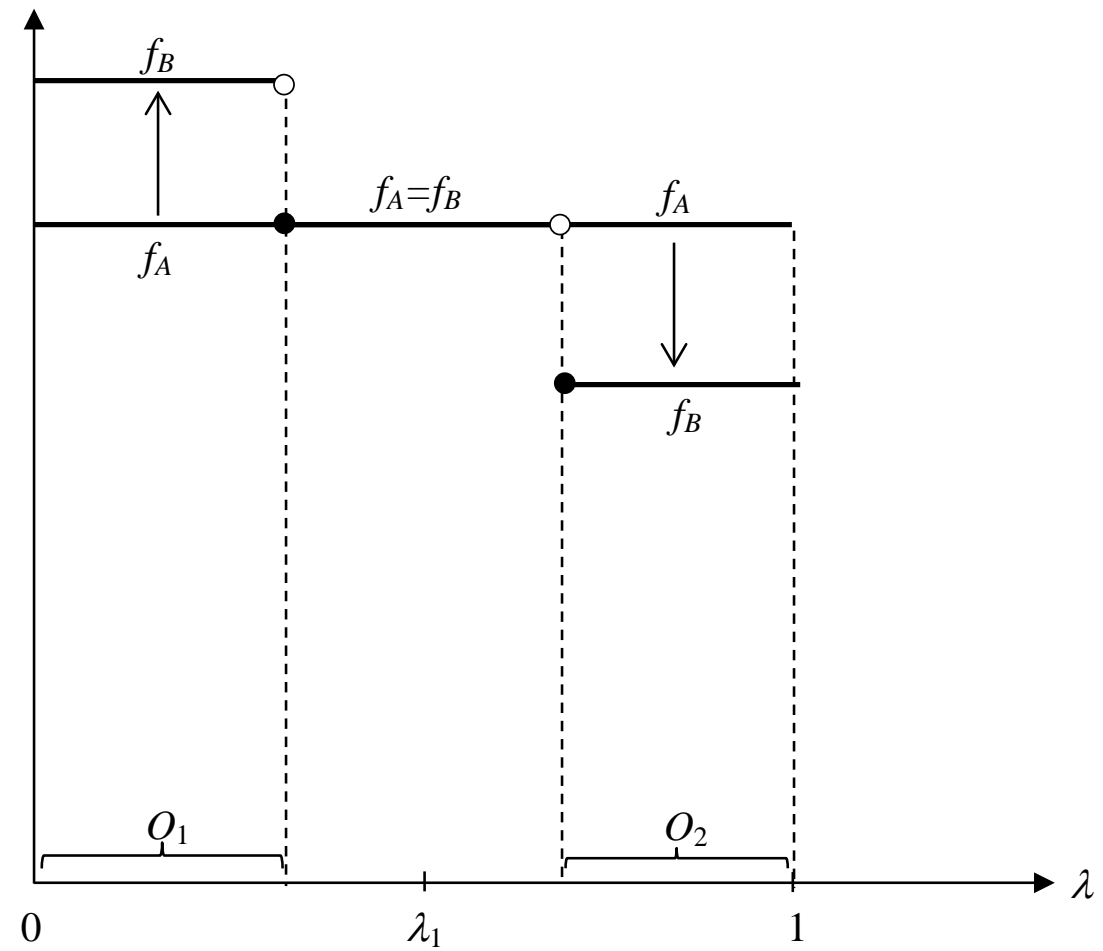

Figure 2: Illustration of part (ii) of Proposition 3. $\Delta^{M Q S, S L}$ under the distribution of $\lambda$ with density $f_{B}$ exceeds $\Delta^{M Q S, S L}$ under the distribution of $\lambda$ with density $f_{A}$. 


\section{Appendix}

\section{Proof that $x^{L F}(\lambda, h)$ and $p^{L F}(\lambda, h)$ are increasing in both $\lambda$ and $h$ :}

Differentiating both sides of (5) with respect to $\lambda$ gives:

$$
-\pi^{\prime \prime}\left(x^{L F}(\lambda, h)\right) \frac{\partial x^{L F}(\lambda, h)}{\partial \lambda}=-\frac{1}{h \lambda^{2}} .
$$

Thus,

$$
\frac{\partial x^{L F}(\lambda, h)}{\partial \lambda}=\frac{1}{h \lambda^{2} \pi^{\prime \prime}\left(x^{L F}(\lambda, h)\right)} .
$$

Similarly, differentiating both sides of (5) with respect to $h$ and rearranging terms gives:

$$
\frac{\partial x^{L F}(\lambda, h)}{\partial h}=\frac{1}{\lambda h^{2} \pi^{\prime \prime}\left(x^{L F}(\lambda, h)\right)} .
$$

Because $\pi^{\prime \prime}>0$, the right-hand side of (A2) and (A3) is positive. Since $p^{L F}(\lambda, h)=x^{L F}(\lambda, h)$, it follows that $\partial p^{L F}(\lambda, h) / \partial \lambda>0$ and $\partial p^{L F}(\lambda, h) / \partial h>0$.

\section{Proof that $p^{S L}(\lambda, h, d)$ is increasing in all three of its arguments:}

Differentiating both sides of expression (9) in turn with respect to $\lambda, h$, and $d$, and rearranging terms gives:

$$
\begin{gathered}
\frac{\partial p^{S L}(\lambda, h, d)}{\partial \lambda}=\frac{\partial x^{S L}(\lambda, h, d)}{\partial \lambda}\left[1+\pi^{\prime}\left(x^{S L}(\lambda, h, d)\right) \cdot d\right] \\
\frac{\partial p^{S L}(\lambda, h, d)}{\partial h}=\frac{\partial x^{S L}(\lambda, h, d)}{\partial h}\left[1+\pi^{\prime}\left(x^{S L}(\lambda, h, d)\right) \cdot d\right] \\
\frac{\partial p^{S L}(\lambda, h, d)}{\partial d}=\frac{\partial x^{S L}(\lambda, h, d)}{\partial d}\left[1+\pi^{\prime}\left(x^{S L}(\lambda, h, d)\right) \cdot d\right]+\pi\left(x^{S L}(\lambda, h, d)\right)
\end{gathered}
$$

The terms $\partial x^{S L}(\lambda, h, d) / \partial \lambda, \partial x^{S L}(\lambda, h, d) / \partial h$, and $\partial x^{S L}(\lambda, h, d) / \partial d$ are all positive (proof is analogous to the proof above showing that $\partial x^{L F}(\lambda, h) / \partial \lambda>0$ and $\partial x^{L F}(\lambda, h) / \partial h>0$, and thus omitted). To sign the term $1+\pi^{\prime}\left(x^{S L}(\lambda, h, d)\right) d$ appearing on the right-hand side of (A4)-(16), note that the function $x+\pi(x) d$ is strictly convex and attains minimum at $x=x(d)$ where $x(d)$ is defined by $1+\pi^{\prime}(x(d)) d=0$ or, equivalently, by $-\pi^{\prime}(x(d))=1 / d$. Since $d<\lambda h+(1-\lambda) d$ when $d>h$ it follows that $1 / d>1 /(\lambda h+(1-\lambda) d)$ and, therefore, $x^{S L}(\lambda, h, d)>x(d)$ because $\pi^{\prime \prime}<0$. Hence, $1+\pi^{\prime}\left(x^{S L}(\lambda, h, d)\right) d>0$. Moreover, $\pi\left(x^{S L}(\lambda, h, d)\right)>0$. It follows that the right-hand side of (A4)-(A6) is positive. 


\section{Proof of Proposition 1:}

For $\lambda<1, x^{L F}(\lambda, h)<x^{S L}(\lambda, h, d)<x^{F B}(h)$. Because the function $u-x-\pi(x) h$ is increasing in $x$ for all $x<x^{F B}(h)$,

$$
u-x^{L F}(\lambda, h)-\pi\left(x^{L F}(\lambda, h)\right) h<u-x^{S L}(\lambda, h, d)-\pi\left(x^{S L}(\lambda, h, d)\right) h .
$$

For $\lambda=1, x^{L F}(\lambda, h)=x^{S L}(\lambda, h, d)=x^{F B}(h)$ and

$$
u-x^{L F}(\lambda, h)-\pi\left(x^{L F}(\lambda, h) h=u-x^{S L}(\lambda, h, d)-\pi\left(x^{S L}(\lambda, h, d)\right) h .\right.
$$

Figure 1 illustrates (A7) and (A8). Upon comparing expressions (10) and (7), it follows that $W^{S L}>W^{L F}$ for any $d \in(0, h]$.

\section{Proof of Proposition 2:}

Suppose that $u-x^{L F}(\lambda, h)-\pi\left(x^{L F}(\lambda, h)\right) h<0 \quad$ as $\lambda \rightarrow 0$. Hence, under laissez-faire $u-x^{L F}(\lambda, h)-\pi\left(x^{L F}(\lambda, h)\right) h<0$ for sufficiently small values of $\lambda$ (see Figure 1), where $u-x^{L F}(\lambda, h)-\pi\left(x^{L F}(\lambda, h)\right) h$ is strictly increasing in $\lambda$ because $\partial x^{L F}(\lambda, h) / \partial \lambda>0$ and $-1-\pi^{\prime}\left(x^{L F}(\lambda, h)\right) h>0$. To choose a social welfare-maximizing minimum quality standard, the regulator sets $x^{M Q S}>0$ such that $u-x^{M Q S}-\pi\left(x^{M Q S}\right) h=0$ and $u-x-\pi(x) h>0$ for all $x>x^{M Q S}$. Thus, the right-hand side of expression (11) exceeds the right-hand side of expression (7) and $W^{M Q S}>W^{L F}$. In contrast, if $u-x^{L F}(\lambda, h)-\pi\left(x^{L F}(\lambda, h)\right) h \geq 0$ for all $\lambda \in(0,1]$, the social welfare-maximizing minimum quality standard equals $x^{M Q S}=0$ and $W^{M Q S}=W^{L F}$.

\section{Proof of Proposition 3:}

Suppose, first, that $u-x^{S L}(\lambda, h, d)-\pi\left(x^{S L}(\lambda, h, d)\right) h>0$ for all $\lambda \in(0,1]$. Then, the term in the brackets in (10) is strictly positive. Moreover, because (A7) holds for all $\lambda \in(0,1)$, it follows that $\Delta^{M Q S, S L}<0$. This proves part 1 of Proposition 3.

Suppose, next, that $u-x^{S L}(\lambda, h, d)-\pi\left(x^{S L}(\lambda, h, d)\right) h<0 \quad$ as $\quad \lambda \rightarrow 0$. Thus, $u-x^{S L}(\lambda, h, d)-\pi\left(x^{S L}(\lambda, h, d)\right) h<0$ for sufficiently small values of $\lambda$ (see Figure 1 ). Recall that

$$
\begin{aligned}
\Delta^{M Q S, S L}= & \int_{\lambda_{0}(h)}^{1}\left[u-x^{L F}(\lambda, h)-\pi\left(x^{L F}(\lambda, h)\right) h\right] f(\lambda) d \lambda \\
& \quad-\int_{0}^{1}\left[u-x^{S L}(\lambda, h, d)-\pi\left(x^{S L}(\lambda, h, d)\right) h\right] f(\lambda) d \lambda .
\end{aligned}
$$

To establish the effect of $d$ on $\Delta^{M Q S, S L}$, differentiate the right-hand side of (A9) with respect to $d$ : 


$$
\frac{\partial \Delta^{M Q S, S L}}{\partial d}=-\int_{0}^{1}\left\{\frac{\partial x^{S L}(\lambda, h, d)}{\partial d}\left[-1-\pi^{\prime}\left(x^{S L}(\lambda, h, d)\right) h\right]\right\} f(\lambda) d \lambda .
$$

In the integrand of (A10), $\partial x^{S L}(\lambda, h, d) / \partial d>0$ and $-1-\pi^{\prime}\left(x^{S L}(\lambda, h, d)\right) h>0$. Therefore, the right-hand side of (A10) is negative. Moreover, $u-x^{S L}(\lambda, h, d)-\pi\left(x^{S L}(\lambda, h, d)\right) h \rightarrow u-x^{F B}(h)-\pi\left(x^{F B}(h)\right) h>0$ as $d \rightarrow h$. Thus $\Delta^{M Q S, S L}<0$ for $d$ sufficiently close to $h$.

To establish the effect of $u$ on $\Delta^{M Q S, S L}$, differentiate the right-hand side of (A9) with respect to $u$ :

$$
\frac{\partial \Delta^{M Q S, S L}}{\partial u}=\int_{\lambda_{0}(h)}^{1} f(\lambda) d \lambda-\int_{0}^{1} f(\lambda) d \lambda=-F\left(\lambda_{0}(h)\right),
$$

where $F(\cdot)$ is the cumulative density function of $\lambda$. Since $\lambda_{0}(h)>0, F\left(\lambda_{0}(h)\right)>0$ and the right-hand side of (A11) is negative. Moreover, for $u$ sufficiently large, $\Delta^{M Q S, S L}<0$. This proves part 2(i) of Proposition 3.

Next, define the following function:

$$
\Psi(\lambda)= \begin{cases}-\left[u-x^{S L}(\lambda)-\pi\left(x^{S L}(\lambda)\right) h\right] & \text { if } \lambda \in\left(0, \lambda_{1}\right] \\ -\left[u-x^{S L}(\lambda)-\pi\left(x^{S L}(\lambda)\right) h\right] & \text { if } \lambda \in\left(\lambda_{1}, \lambda_{0}\right] \\ {\left[u-x^{N L}(\lambda)-\pi\left(x^{N L}(\lambda)\right) h\right]-\left[u-x^{S L}(\lambda)-\pi\left(x^{S L}(\lambda)\right) h\right]} & \text { if } \lambda \in\left(\lambda_{0}, 1\right]\end{cases}
$$

where we suppress dependence of $x^{L F}$ on $h$ and $x^{S L}$ on $h$ and $d$. Note that $\Psi(\lambda)>0$ for $\lambda \in\left(0, \lambda_{1}\right)$ and $\Psi(\lambda)<0$ for $\lambda \in\left(\lambda_{1}, \lambda_{0}\right)$ and $\lambda \in\left(\lambda_{0}, 1\right)$; see Figure 1 . Moreover, $\int_{0}^{1} \Psi(\lambda) d F(\lambda)=\Delta^{M Q S, S L}$. Now assume that the statements (a) and (b) in part 2(ii) of Proposition 3 hold. Then

$$
F_{B}(\lambda)=\int_{0}^{\lambda} f_{B}(\lambda) d \lambda \geq \int_{0}^{\lambda} f_{A}(\lambda) d \lambda=F_{A}(\lambda)
$$

for all $\lambda \in\left(0, \lambda_{1}\right)$ and

$$
1-F_{B}(\lambda)=\int_{\lambda}^{1} f_{B}(\lambda) d \lambda \leq \int_{\lambda}^{1} f_{A}(\lambda) d \lambda=1-F_{A}(\lambda) .
$$

or, equivalently, $F_{B}(\lambda) \geq F_{A}(\lambda)$ for all $\lambda \in\left(\lambda_{1}, 1\right)$. Thus, $F_{B}(\lambda) \geq F_{A}(\lambda)$ for all $\lambda \in(0,1]$ : the distribution A first-order stochastically dominates distribution $B$. To prove part 2(ii) of the result, we need to show that $\Delta^{M Q S, S L}$ under $F_{B}(\lambda)$ is greater than $\Delta^{M Q S, S L}$ under $F_{A}(\lambda)$, that is, that

$$
\int_{0}^{1} \Psi(\lambda) f_{B}(\lambda) d \lambda>\int_{0}^{1} \Psi(\lambda) f_{A}(\lambda) d \lambda
$$


or, equivalently, that

$$
\int_{0}^{\lambda_{1}} \Psi(\lambda) f_{B}(\lambda) d \lambda>\int_{0}^{\lambda_{1}} \Psi(\lambda) f_{A}(\lambda) d \lambda
$$

and

$$
\int_{\lambda_{1}}^{1} \Psi(\lambda) f_{B}(\lambda) d \lambda>\int_{\lambda_{1}}^{1} \Psi(\lambda) f_{A}(\lambda) d \lambda .
$$

To show that (A16) is true, write

$$
\int_{0}^{\lambda_{1}} \Psi(\lambda)\left[f_{B}(\lambda)-f_{A}(\lambda)\right] d \lambda=\int_{O_{1}} \Psi(\lambda)\left[f_{B}(\lambda)-f_{A}(\lambda)\right] d \lambda+\int_{\left(0, \lambda_{1} \backslash O_{1}\right.} \Psi(\lambda)\left[f_{B}(\lambda)-f_{A}(\lambda)\right] d \lambda .
$$

Recall that $\Psi(\lambda)>0$ for $\lambda \in\left(0, \lambda_{1}\right)$. Moreover, by condition (a) in part 2(ii) of Proposition 3, $f_{B}(\lambda)>f_{A}(\lambda)$ for $\lambda \in O_{1}$ and $f_{B}(\lambda) \geq f_{A}(\lambda)$ for $\lambda \in\left(0, \lambda_{1}\right] \backslash O_{1}$. Thus, the right-hand side of (A18) is positive and (A16) holds. To show that (A17) is true, write

$$
\int_{\lambda_{1}}^{1} \Psi(\lambda)\left[f_{B}(\lambda)-f_{A}(\lambda)\right] d \lambda=\int_{O_{2}} \Psi(\lambda)\left[f_{B}(\lambda)-f_{A}(\lambda)\right] d \lambda+\int_{\left[\lambda_{1}, 1\right] O_{2}} \Psi(\lambda)\left[f_{B}(\lambda)-f_{A}(\lambda)\right] d \lambda .
$$

Recall that $\Psi(\lambda)<0$ for $\lambda \in\left(\lambda_{1}, \lambda_{0}\right)$ and $\lambda \in\left(\lambda_{0}, 1\right)$. Moreover, by condition (b) in part 2(ii) of Proposition 3, $f_{B}(\lambda)<f_{A}(\lambda)$ for $\lambda \in O_{2}$ and $f_{B}(\lambda) \leq f_{A}(\lambda)$ for $\lambda \in\left[\lambda_{1}, 1\right] \backslash O_{2}$. Thus, the right-hand side of (A19) is positive and (A17) holds. Hence, (A15) holds. This proves part 2(ii) of Proposition 3.

To ascertain the effect of $h$ on $\Delta^{M Q S, S L}$, differentiate the right-hand side of (A9) with respect to $h$ :

$$
\begin{aligned}
\frac{\partial \Delta^{M Q S, S L}}{\partial h}= & -\left[u-x^{L F}\left(\lambda_{0}(h), h\right)-\pi\left(x^{L F}\left(\lambda_{0}(h), h\right)\right) h\right] f\left(\lambda_{0}(h)\right) \lambda_{0}^{\prime}(h) \\
& +\int_{\lambda_{0}(h)}^{1}\left\{\frac{\partial x^{L F}(\lambda, h)}{\partial h}\left[-1-\pi^{\prime}\left(x^{L F}(\lambda, h)\right) h\right]-\pi\left(x^{L F}(\lambda, h)\right)\right\} f(\lambda) d \lambda \\
& -\int_{0}^{1}\left\{\frac{\partial x^{L L}(\lambda, h, d)}{\partial h}\left[-1-\pi^{\prime}\left(x^{S L}(\lambda, h, d)\right) h\right]-\pi\left(x^{S L}(\lambda, h, d)\right)\right\} f(\lambda) d \lambda .
\end{aligned}
$$

Because $u-x^{L F}\left(\lambda_{0}(h), h\right)-\pi\left(x^{L F}\left(\lambda_{0}(h), h\right)\right) h=0$, the first term on the right-hand side of (A20) equals zero. The sign of the second and third term, however, is ambiguous. For a given regime $r \in\{L F, S L\}$, we have $\left[\partial x^{r} / \partial h\right]\left[-1-\pi^{\prime}\left(x^{r}\right) h\right]>0$ and, at the same time, $\pi\left(x^{r}\right)>0$. Thus, the sign of the expression $\left[\partial x^{r} / \partial h\right]\left[-1-\pi^{\prime}\left(x^{r}\right) h\right]-\pi\left(x^{r}\right)$ is ambiguous and, hence, so is the sum of the second and third term in (A20). To further illustrate this point, rewrite the right-hand side of (A20) as: 


$$
\begin{gathered}
\int_{\lambda_{0}(h)}^{1}\left\{\frac{\partial x^{L F}}{\partial h}\left[-1-\pi^{\prime}\left(x^{L F}\right) h\right]-\frac{\partial x^{S L}}{\partial h}\left[-1-\pi^{\prime}\left(x^{S L}\right) h\right]-\left[\pi\left(x^{L F}\right)-\pi\left(x^{S L}\right)\right]\right\} f(\lambda) d \lambda \\
-\int_{0}^{\lambda_{0}(h)}\left\{\frac{\partial x^{S L}}{\partial h}\left[-1-\pi^{\prime}\left(x^{S L}\right) h\right]-\pi\left(x^{S L}\right)\right\} f(\lambda) d \lambda .
\end{gathered}
$$

In the first term of (A21), we have $\left[\partial x^{L F} / \partial h\right]\left[-1-\pi^{\prime}\left(x^{L F}\right) h\right]>0$, but also $\left[\partial x^{L F} / \partial h\right]\left[-1-\pi^{\prime}\left(x^{L F}\right) h\right]>0$ and $\pi\left(x^{L F}\right)-\pi\left(x^{S L}\right)>0$ because $x^{L F}>x^{S L}$. Thus, the first term in (A21) is ambiguous in sign. In the second term, [ $\left.\partial x^{S L} / \partial h\right]\left[-1-\pi^{\prime}\left(x^{S L}\right) h\right]-\pi\left(x^{S L}\right)$ is ambiguous in sign for reasons noted above. Therefore, the difference between the first and the second term is ambiguous in sign. This illustrates part 2(iii) of Proposition 3.

\section{Proof of Proposition 4:}

When $u-x^{S L}(\lambda, h, d)-\pi\left(x^{S L}(\lambda, h, d)\right) h>0$ for all $\lambda \in(0,1]$, proof of points (i)-(iii) in part 1 of Proposition 4 is straightforward and thus omitted; see the discussion in Section 5. When $u-x^{S L}(\lambda, h, d)-\pi\left(x^{S L}(\lambda, h, d)\right) h<0$ as $\lambda \rightarrow 0$, points (i) and (ii) in part 2 of the result can likewise be readily established. To prove part 2(iii) of Proposition 4, note that when $u-x^{S L}(\lambda, h, d)-\pi\left(x^{S L}(\lambda, h, d)\right) h<0$ as $\lambda \rightarrow 0, W^{M Q S+S L}-W^{M Q S}$ equals

$$
\int_{\lambda_{1}}^{1}\left[u-x^{S L}(\lambda)-\pi\left(x^{S L}(\lambda)\right) h\right] f(\lambda) d \lambda-\int_{\lambda_{0}}^{1}\left[u-x^{N L}(\lambda)-\pi\left(x^{N L}(\lambda)\right) h\right] f(\lambda) d \lambda,
$$

where we again suppress dependence on $h$ and $d$. (A22) can in turn be expressed as

$$
\begin{aligned}
\int_{\lambda_{1}}^{\lambda_{0}}\left[u-x^{S L}(\lambda)\right. & \left.-\pi\left(x^{S L}(\lambda)\right) h\right] f(\lambda) d \lambda \\
& +\int_{\lambda_{0}}^{1}\left\{\left[u-x^{S L}(\lambda)-\pi\left(x^{S L}(\lambda)\right) h\right]-\left[u-x^{N L}(\lambda)-\pi\left(x^{N L}(\lambda)\right) h\right]\right\} f(\lambda) d \lambda
\end{aligned}
$$

or, equivalently, as

$$
\int_{\lambda_{1}}^{1}-\Psi(\lambda) f(\lambda) d \lambda
$$

where $\Psi(\lambda)$ is defined in (A12). Recall that $\Psi(\lambda)<0$ for $\lambda \in\left(\lambda_{1}, 1\right]$. Thus, expression (A24) is positive and $W^{M Q S+S L}>W^{M Q S}$.

Similarly, $W^{M Q S+S L}-W^{S L}$ equals 


$$
\int_{\lambda_{1}}^{1}\left[u-x^{S L}(\lambda)-\pi\left(x^{S L}(\lambda)\right) h\right] f(\lambda) d \lambda-\int_{0}^{1}\left[u-x^{S L}(\lambda)-\pi\left(x^{S L}(\lambda)\right) h\right] f(\lambda) d \lambda .
$$

Expression (A25) can in turn be written as

$$
-\int_{0}^{\lambda_{1}}\left[u-x^{S L}(\lambda)-\pi\left(x^{S L}(\lambda)\right) h\right] f(\lambda) d \lambda
$$

or, equivalently, as

$$
\int_{0}^{\lambda_{1}} \Psi(\lambda) f(\lambda) d \lambda
$$

Recall that $\Psi(\lambda)>0$ for all $\lambda \in\left(0, \lambda_{1}\right.$. Thus, expression (A27) is positive and $W^{M Q S+S L}>W^{S L}$. 